\title{
Near-future Options of Electricity Generation for Sustainable Development: Trends and Prospects
}

\author{
FAZLUR RASHID ${ }^{1}$ and Mohammad U. H. Joardder ${ }^{1}$ \\ ${ }^{1}$ Rajshahi University of Engineering and Technology
}

July 11, 2021

\begin{abstract}
Electricity is an important part of our daily life and uses for different purposes. However, electricity generation sources are decreasing day by day and electricity mainly generates from renewable and conventional sources of energy. Proper management to create new conventional energy sources is challenging all over the world. Lack of conventional sources of energy, high demand for energy, less available land, and low budget for energy are some of the important factors that cause poor energy management all over the world. In this paper, different potential less attributed sources of energy are analyzed along with their implementation techniques to mitigate high electricity demand in near-future. This review shows that along with renewable and conventional sources of energy, less attended energy sources would be a potential source that can generate electricity. This review also presents that no improved techniques are needed to implement less attended sources of energy and can be implemented with sustainable techniques. This study also proposes implementation techniques of uncommon sources of energy for electricity generation with related challenges that could emerge during the implementation of these sources of energy. In this study, the electricity generation rate and their corresponding applications are also depicted. Proper steps and execution of less attended sources of energy would mitigate high energy demand all over the world and offers a cleaner environment for livelihood.
\end{abstract}

\section{Hosted file}

Manuscript.docx available at https://authorea.com/users/424927/articles/529904-near-futureoptions-of-electricity-generation-for-sustainable-development-trends-and-prospects 